\title{
Consumption of alcohol, cigarettes and illegal substances among physicians and medical students in Brandenburg and Saxony (Germany)
}

\author{
Karen Voigt ${ }^{* 1}$, Sabine Twork ${ }^{2}$, Dirk Mittag ${ }^{1}$, Anne Göbel ${ }^{1}$, Roger Voigt ${ }^{1}$, \\ Jörg Klewer ${ }^{3}$, Joachim Kugler ${ }^{2}$, Stefan R Bornstein ${ }^{4}$ and Antje Bergmann ${ }^{1}$
}

\begin{abstract}
Address: ${ }^{1}$ Department of General Medicine/Medical Clinic III, Dresden Medical School, Dresden University of Technology, Dresden, Germany, ${ }^{2}$ Department of Public Health, Dresden Medical School, Dresden University of Technology, Dresden, Germany, ${ }^{3}$ Department of Public Health and Health Care Management, University of Applied Sciences Zwickau, Zwickau, Germany and ${ }^{4}$ Medical Clinic III, University Hospital Carl Gustav Carus of the Dresden University of Technology, Dresden, Germany

Email: Karen Voigt* - Karen.Voigt@uniklinikum-dresden.de; Sabine Twork - sabine_twork@hotmail.com; Dirk Mittag - dirk.mittag@hausarzthlp.de; Anne Göbel - la.pluie@web.de; Roger Voigt - praxis.drvoigt@web.de; Jörg Klewer - joklewer@aol.com; Joachim Kugler - jokugler@aol.com; Stefan R Bornstein - stefan.bornstein@uniklinikum-dresden.de; Antje Bergmann - Antje.Bergmann@uniklinikum-dresden.de

* Corresponding author
\end{abstract}

This article is available from: http://www.biomedcentral.com/l472-6963/9/219

(c) 2009 Voigt et al; licensee BioMed Central Ltd.

This is an Open Access article distributed under the terms of the Creative Commons Attribution License (http://creativecommons.org/licenses/by/2.0), which permits unrestricted use, distribution, and reproduction in any medium, provided the original work is properly cited.

\begin{abstract}
Background: Patients regard health care professionals as role models for leading a healthy lifestyle. Health care professionals' own behaviour and attitudes concerning healthy lifestyle have an influence in counselling patients. The aim of this study was to assess consumption of alcohol, cigarettes and illegal substances among physicians and medical students in two German states: Brandenburg and Saxony.
\end{abstract}

Methods: Socio-demographic data and individual risk behaviour was collected by an anonymous self-administered questionnaire. Physicians were approached via mail and students were recruited during tutorials or lectures.

Results: $41.6 \%$ of physicians and $60.9 \%$ of medical students responded to the questionnaire; more than $50 \%$ of the respondents in both groups were females. The majority of respondents consumed alcohol at least once per week; median daily alcohol consumption ranged from $3.88 \mathrm{~g} / \mathrm{d}$ (female medical students) to $12.6 \mathrm{~g} / \mathrm{d}$ (male physicians). A significantly higher percentage of men $(p<0.05)$ reported hazardous or harmful drinking compared to women. A quarter of all participating physicians and one third of all students indicated unhealthy alcohol-drinking behaviour. The majority of physicians $(85.7 \%)$ and medical students $(78.5 \%)$ were non-smokers. Both groups contained significantly more female non-smokers $(p<0.05)$. Use of illegal substances was considerably lower in physicians $(5.1 \%)$ than medical students $(33.0 \%)$. Male students indicated a significantly $(\mathrm{p}<0.00 \mathrm{I})$ higher level of illegal drug-use compared to female students.

Conclusion: More than one third of the medical students and health care professionals showed problematic alcoholdrinking behaviour. Although the proportion of non-smokers in the investigated sample was higher than in the general population, when compared to the general population, medical students between 18-24 reported higher consumption of illegal substances.

These results indicate that methods for educating and promoting healthy lifestyle, particularly with respect to excessive alcohol consumption, tobacco use and abuse of illegal drugs should be considered. 


\section{Background}

Alcohol consumption, smoking and illegal drug use are important health indicators in accordance with the results of European Community Health Indicators project (ECHI) within the European Commissions Health Monitoring Programme [1]. According to the German Report of Drugs and Addiction [2], approximately 16 million German adults (34\%) are smokers and more than 9 million German adults (31\% male and $16 \%$ female) consume inappropriate levels of alcohol. Five percent of German adults reported use of illegal drugs in the previous 12 months [3].

This indicates a need to educate the German population about the potential negative consequences of alcohol, cigarette smoking and abuse of illegal substances. Physicians play an important role in health education and are often expected to serve as role models for a healthy lifestyle [46]. Physicians who lead an unhealthy lifestyle themselves might provide their patients with less effective advice on this topic than their more health-conscious colleagues $[7,8]$. This study attempts to assess the prevalence of cigarette smoking and level of consumption of alcohol and illegal substances among physicians and medical students.

\section{Methods}

Between April 2004 and May 2006 a voluntary survey was conducted by the Department of General Medicine at the Dresden Medical School. Anonymous questionnaires together with a letter of motivation and prepaid envelope were mailed to all private practice physicians (i.e. general practitioners and surgeons) registered at the National Association of Statuary Health Insurance of Brandenburg and Saxony. Medical students in the 1st, 3rd and 5th academic years at the Dresden Medical School (one of the two public Medical Schools in Saxony) were asked to complete similar questionnaires during tutorials or lectures.

\section{Questionnaire and statistics}

The questionnaire was based on several former surveys [9] and collected information on socio-demographic data, health status (e.g. body mass index, subjective experienced individual health status), occupational stress and reported health behaviour (e.g. consumption of alcohol, cigarettes and illegal substances, received vaccinations [10]). Participants were asked the quantity and type of alcohol consumed in litres per average week. To standardize the data for comparison, litres were converted to grams of alcohol consumed per day (g/d) in calculating daily ingestions. Reference values used for these calculations [11] were: 1 ) wine: $0.125 \mathrm{l}$ of wine was considered as $11 \mathrm{~g}$ of alcohol; 2) beer and mixed drinks: $0.33 \mathrm{l}$ of beer and $0.275 \mathrm{l}$ of mixed drinks were considered as $13 \mathrm{~g}$ of alco- hol, and; 3 ) spirits: $4 \mathrm{cl}$ was considered as $11 \mathrm{~g}$ of alcohol [12].

All participants were asked to describe their current smoking behaviour and the number of cigarettes smoked daily as well as previous consumption of illegal substances. There was no specific definition of illegal substances in the questionnaire. Data was analysed using SPSS 15.0. Descriptive analysis and nonparametric statistics $\left(\chi^{2}-\right.$ tests) were performed, and the level of significance was defined at $\mathrm{p}<0.05$. In comparing different groups, missing values were pairwise deleted.

\section{Samples}

The total number of responses was 940 with 642 registered physicians and 298 medical students participating. The response rate was $41.6 \%$ for the physicians and $60.9 \%$ for the students.

The majority of medical students were under the age of 30 years, while the majority of physicians were older than 30 years. The proportion of females was higher in both groups (58.8\% and $58.4 \%$, respectively, see Table 1$)$. The number of students was evenly distributed among each of the three academic years (33.0\%).

\section{Results \\ Alcohol consumption}

More than $75 \%$ of the participants reported consumption of alcohol one or more times during an average week. The majority of the respondents $(82.5 \%$ physicians, $62.8 \%$ medical students) drank wine every week, whereas $40 \%$ in both groups consumed beer. As the questioning only addressed weekly consumption, it was not possible to identify the phenomenon of binge drinking [2].

The average amount of alcohol consumed among the medical students was significantly higher than among physicians (25.77 vs. $10.88 \mathrm{~g} / \mathrm{d}$, respectively). A comparison of the median values ( $50^{\text {th }}$ percentile) in both groups showed that more students than physicians consumed only few or no amounts of alcohol (5.9 vs. $7.54 \mathrm{~g} / \mathrm{d}$, respectively). Nevertheless, a sub-group of students consuming high quantities of alcohol was identified (see Table 2).

The age and the daily amount of alcohol consumed only correlated significantly in the group of medical students (Kendall-Tau-b, $\mathrm{r}=0.104 / \mathrm{p}=0.05$ ).

$24.8 \%$ of the male physicians and $36.5 \%$ of the male medical students reported higher ingestions than the recommended daily allowance by the German Nutrition Society on maximal alcohol ingestion (MAAI for men: > $20 \mathrm{~g} / \mathrm{d}$ ). Among the female participants, $25.3 \%$ of the 
Table I: Socio-demographic sample data

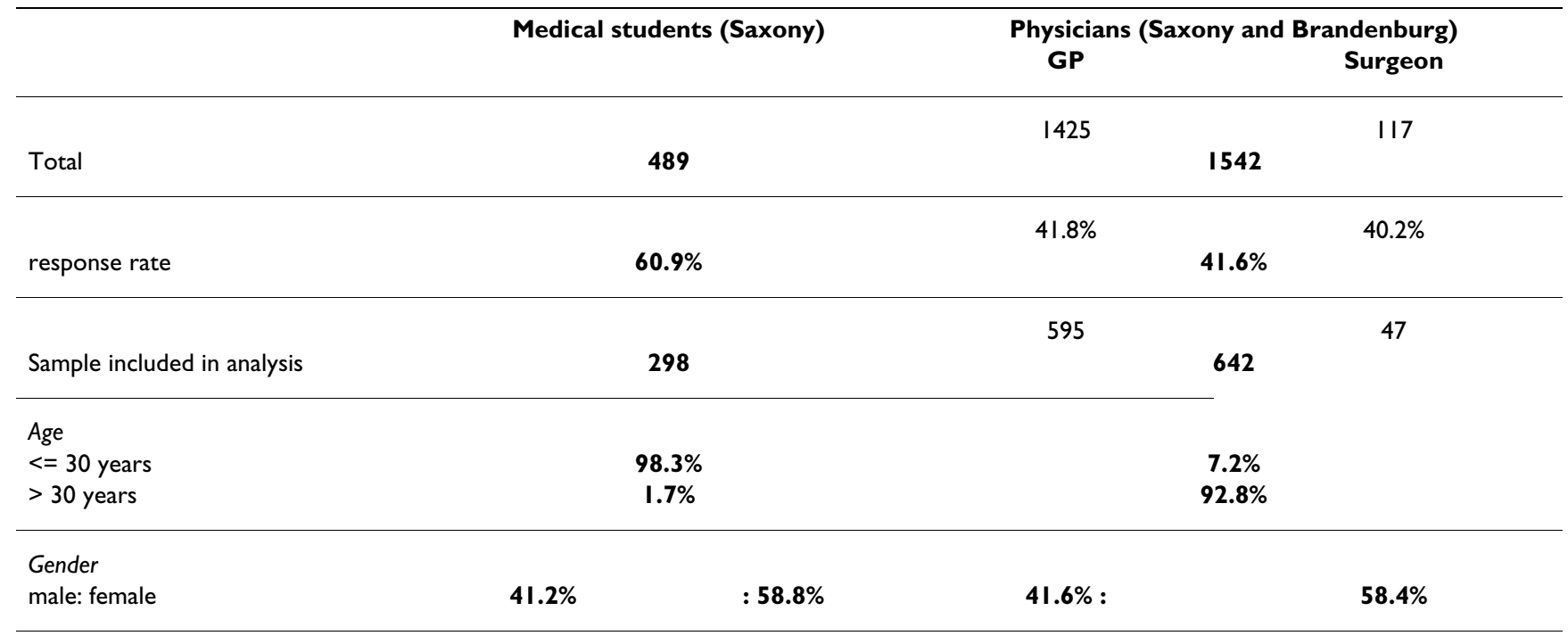

physicians and $30.4 \%$ of the medical students reported higher ingestions of alcohol than the recommended daily allowance (MAAI for women $>10 \mathrm{~g} / \mathrm{d}$ ) [11].

The European Community Health Indicators-Project (ECHI) and the World Health Organisation (WHO) have made distinctions between hazardous and harmful drinking. Hazardous drinking (more than $40 \mathrm{~g} / \mathrm{d}$ for males and more than $20 \mathrm{~g} / \mathrm{d}$ for females) is defined as a level of alcohol consumption that may result in physical or psychological damage [13]. Harmful alcohol consumption (more than $60 \mathrm{~g} / \mathrm{d}$ for males and $40 \mathrm{~g} / \mathrm{d}$ for females) is defined as a drinking behaviour leading to harming of physical or psychological health $[14,15]$. According to these reference values, $17.5 \%$ of the male physicians and $9 \%$ of the male medical students ingested hazardous quantities of alcohol. More than $30 \%$ of the male students but less than $10 \%$ of the male physicians indicated harmful drinking behaviour (see Figure $1, \chi^{2}=31.933 / \mathrm{p}<$ $0.001)$.

More female medical students than female physicians consumed significantly hazardous $(9.2 \%$ vs. $5.8 \%)$ and harmful $(13.8 \%$ vs. $1.9 \%)$ quantities of alcohol $\left(\chi^{2}=\right.$ $33.531 / \mathrm{p}<0.001)$.

\section{Cigarette smoking}

The majority of physicians ( $85.7 \%$ ) and medical students $(78.5 \%)$ were non-smokers. In both groups fewer females than males reported cigarette smoking (see Figure 2).

No significant correlation between age and non-smoking status was found. No significant gender-related differences in smoking were found between physicians and medical students.

Among smokers $(\mathrm{n}=125), 66.4 \%$ reported smoking fewer than ten cigarettes per day, while $27.2 \%$ reported smoking more than ten but fewer than 20 cigarettes per day. $6.4 \%$ of all smokers mentioned a daily smoking rate of more than 20 cigarettes. No relation between age and the number of cigarettes smoked was found.

\section{Consumption of illegal substances}

The majority of physicians (94.9\%) and two-thirds of the medical students $(66.0 \%)$ denied any consumption of

Table 2: Daily alcohol consumption in g/d among medical students and physicians

\begin{tabular}{|c|c|c|c|}
\hline & & Medical students $(\mathrm{n}=\mathbf{2 9 8})$ & $\begin{array}{l}\text { Physicians } \\
(n=642)\end{array}$ \\
\hline Mean +/- standard deviation & & $30.84+/-56.70$ & $11.58+/-15.81$ \\
\hline \multirow[t]{2}{*}{ Mode } & & 0 & 0 \\
\hline & 25 & 0 & 2.51 \\
\hline \multirow[t]{2}{*}{ Quartile } & 50 & 5.89 & 7.54 \\
\hline & 75 & 25.45 & 14.16 \\
\hline
\end{tabular}




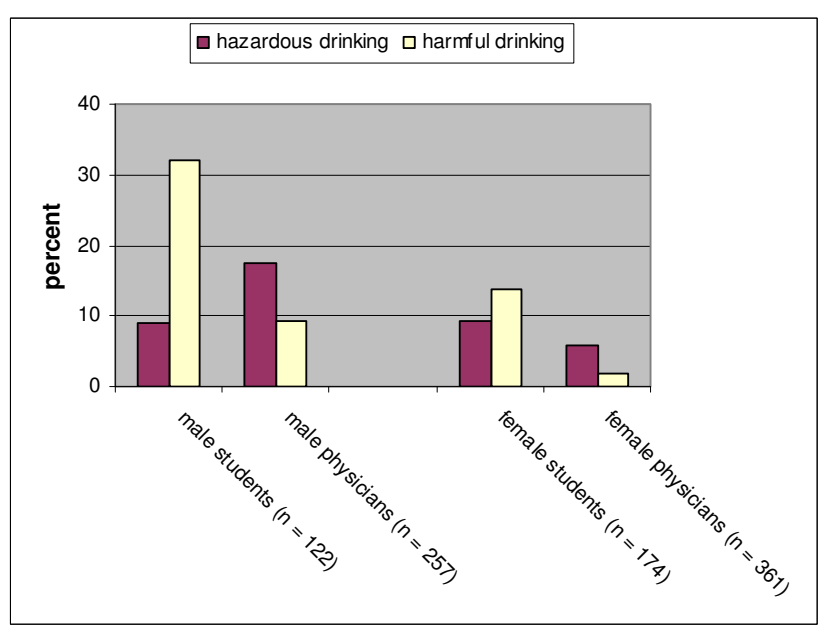

Figure I

proportions of hazardous and harmful drinking among medical students and physicians depending on gender.

illegal substances. Among medical students, fewer female than male students reported consuming illegal substances. Additionally, the one-time or repeated consumption of these substances was significantly lower in female than in male students $\left(\chi^{2}=24,937 / \mathrm{p}<0.001\right.$, see Table 3$)$

No statistical difference in relation to year of matriculation was found in the group of medical students.

\section{Discussion \\ Sampling and methods}

Within the initial distribution group, $61 \%$ of the medical students and $42 \%$ of the physicians responded to the questionnaire. Among other possibilities, such as method of delivery and time constraints, an intensive political discussion at the time broaching the issues of the survey might have influenced the response behaviour.

The difference in the response rate between the groups may have been affected by the distribution methods (direct distribution during classes vs. distribution by post).

Respondents are proportionally comparable in gender and age to those of physicians in Brandenburg and Saxony [16-18] and of medical students at Dresden Medical School. Therefore, study findings appear to be representative for physicians in private practice and medical students in the eastern states of Germany.

Participation in the study was voluntary and anonymous. It remains unclear whether the response rate was associated with consumption rate of alcohol, cigarettes and illegal substances.

\section{Alcohol consumption}

The proportion of current abstinence in the investigated medical students corresponds to a similar study in medical students from Poland and Germany [19]. Compared to findings related to attitudes towards alcohol drinking behaviour in the European Union, the percentage of physicians reporting abstinence was lower than the average

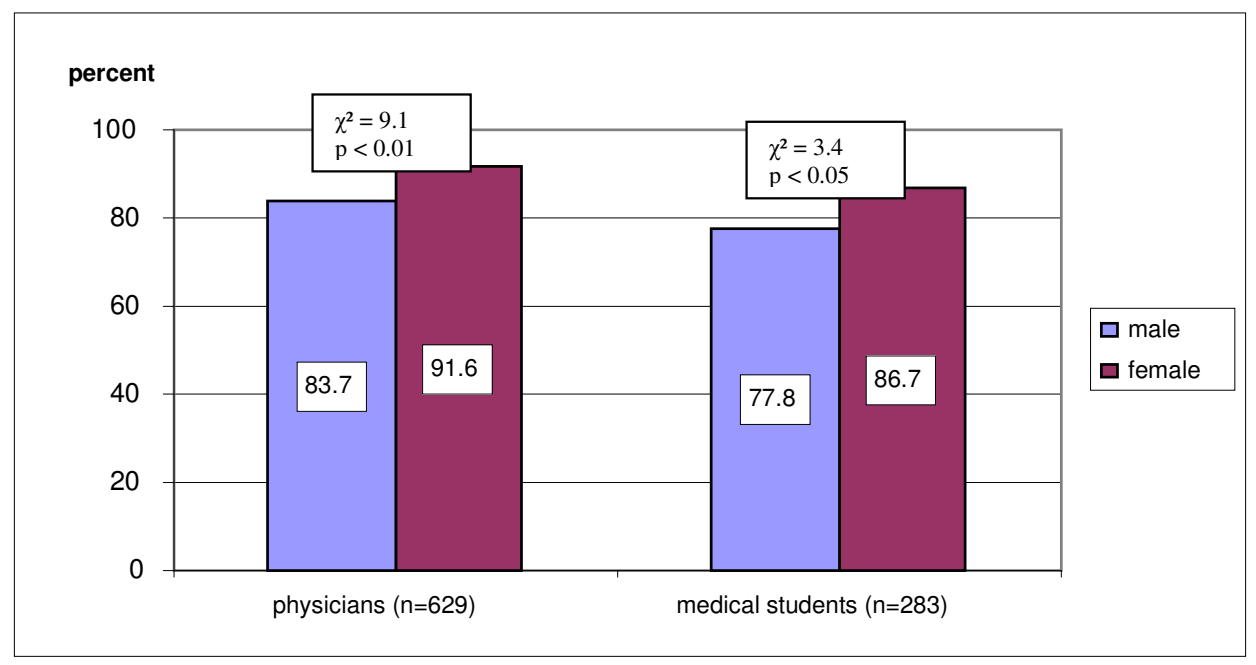

Figure 2

Proportions of female and male non-smokers among medical students and physicians. 
Table 3: Proportions of students and physicians related to consumption of illegal substances

\begin{tabular}{lcccc}
\hline Amount of consumption & \multicolumn{2}{c}{ Medical students $(\mathbf{n}=\mathbf{2 9} \mathbf{I})$} & Physicians (only Brandenburg, $\mathbf{n}=\mathbf{4 8 6})$ \\
\hline Gender & male & female & male & female \\
\hline Never & 49.6 & 77.8 & 92.5 & 96.5 \\
Once & 10.9 & 7.0 & 3.3 & 2.3 \\
Several times & 39.5 & 15.2 & 4.2 & 1.2 \\
\hline
\end{tabular}

percentages in European males (16\%) and females (32\%) [20].

Male physicians report consuming significantly higher amounts of alcohol than female physicians, which corresponds to findings in the general German population $[11,21]$. Furthermore, in comparison to results from a national German health survey [22], the proportion of the investigated male medical students reporting harmful alcohol consumption $(20 \mathrm{~g} / \mathrm{d})$ was higher than in male Germans 18 to 29 years of age (33\% vs. $20 \%$ ), and the proportion of male physicians reporting harmful alcohol consumption (25\%) was lower than in male Germans 30 to 59 years of age (26-32\%) respectively. The proportion of investigated female medical students (30.4\%) and female physicians $(25.3 \%)$ reporting harmful consumption of alcohol $(>10 \mathrm{~g} / \mathrm{d})$ was remarkably higher than in females in the general German population $(7.2 \%$ in the group 18-29 years of age, and $15 \%$ in the group 30-59 years of age respectively) [22]. Additional German [2,12] and European [20] studies presented findings of harmful alcohol consumption in approximately $25 \%$ of the younger population. Consequently, harmful or hazardous consumption of alcohol appears to be a problem in the general German population as well as in health care professionals, especially medical students.

Preventive strategies need to be developed to identify and support health care professionals at risk from high alcohol consumption [12,23]. Moreover, future studies are required to analyse underlying general tendencies, and to determine whether special conditions during medical training (e.g. psychological strains) lead a higher proportion of medical students reporting harmful alcohol consumption. The relationship between alcohol consumption and intake of meals, the time of consumption, and binge drinking should also be studied.

\section{Smoking}

The proportion of cigarette smokers among the investigated group of medical students and physicians is similar to that reported in former studies of health care professionals [24-26]. The percentage in the investigated groups (approximately 25\%) is lower than the percentage of smokers in the general European population (European population: 32\%; general German population: 30\%) [27]. The proportion of non-smokers in this study is higher than in a comparable German population in which $30-45 \%$ of males and $45-55 \%$ of females age $18-29$ years, and $45-70 \%$ of males and $55-85 \%$ of females age $30-59$ years were non-smokers [22]. These significant genderspecific differences correspond to results from different surveys in the general German population [28] as well as the general European population [27], and correspond to previous studies on the health behaviour of medical students $[25,29]$.

Medical education about the risks of smoking does not seem to be enough to lead to non-smoking behaviour. Health care professionals should be assisted in stopping smoking, for example by increasing the number of smokefree health care facilities (e.g. smoke-free hospitals) [30].

\section{Consumption of illegal substances}

The proportion of investigated physicians reporting consumption of illegal substances at least once is equal to the proportion in the general population reporting the same experience ( $5 \%$ versus less than $3 \%$ in the general population), and not lower [22]. In contrast, a French study showed that approximately $20 \%$ of general practitioners had smoked cannabis at least once [31]. The difference might derive from the fact that the majority of investigated physicians grew up in the German Democratic Republic, where illegal substances were not available or difficult to obtain [32].

On the other hand, the proportion of medical students reporting consumption of illegal substances was higher than in the general German population 18-29 years of age (15-25\%) [22]. A Croatian study revealed similar results with 35\% of medical students reporting consumption of illegal substances at least once [33]. The observed genderspecific differences in the group of medical students correspond to findings in the general German population: males reported to have consumed illegal substances three times more often than females [22]. Consequently, medical students require more information about the problems related to the consumption of illegal substances which can result in medical and psychiatric problems as well as legal problems. It can be assumed that most of the 
medical students do not know that a criminal record due to the consumption of illegal substances leads to rejection when applying for medical board registration.

\section{Conclusion}

According to recent studies, the increase of work-related stress in health care professionals leads to an increase in unhealthy coping habits, such as alcohol consumption to relax, smoking to increase the number of breaks during working-hours or using drugs for stimulation or sedation [33-38]. Health care professionals should be supported in their position as role models for healthy lifestyle. Intensified education concerning healthy lifestyle and coping with consumption of alcohol, cigarettes and illegal substances during medical school could help improve these habits in health care professionals and their patients.

More studies are needed to investigate how early training concerning lifestyle improves health behaviour of health care professionals, and how this can optimise health consulting.

\section{Competing interests}

The authors declare that they have no competing interests.

\section{Authors' contributions}

$\mathrm{AB}$ conceived and designed the study. DM, AG and RV led the data collection. KV and $\mathrm{AB}$ analyzed and interpreted the data. ST assisted in data interpretation. KV drafted the manuscript. SRB, JK1 and JK2 critically reviewed the manuscript. All authors read and approved the final manuscript.

\section{Acknowledgements}

We are grateful for the cooperation and the time invested by the physicians and medical students that participated in this study.

\section{References}

I. Kramers PG: The ECHI project: health indicators for the European Community I. Eur J Public Health 2003, 13:10I-106.

2. Bätzing S: Drogen- und Suchtbericht: Mai. 2008 [http:// www.bmg.bund.de/cln 040/nn 600II0/SharedDocs/Download/DE/ Themenschwerpunkte/Drogen-und-Sucht/Drogen-Suchtbericht08 ,templateld=raw, property=publicationFile.pdf/Drogen-

Suchtbericht-08.pdf]. Drogenbeauftragte der Bundesregierung and Bundesministerium für Gesundheit [last access: 21.05.2008] 2008.

3. Pfeiffer-Gerschel T, Kippke I, David-Spickermann M, Bartsch G: Bericht 2007 des nationalen REITOX-Knotenpunkts an die EBDD. Deutschland. Neue Entwicklungen, Trends und Hintergrundinformationen zu Schwerpunktthemen. Drogensituation 2006/2007 [http://www.dbdd.de]. (last access: 21.05 .2008 ). 2007.

4. Barengo NC, Sandstrom HP, Jormanainen VJ, Myllykangas MT: Attitudes and behaviours in smoking cessation among general practitioners in Finland 200I 148. Soz Praventivmed 2005, 50:355-360.

5. Slama K, Karsenty S, Hirsch A: Do French general practitioners change their practises and smoking behaviours after participation in a smoking cessation trial with their patients? Eur J Gen Pract 1996, 12:58-61.
6. Frank E, Breyan J, Elon L: Physician disclosure of healthy personal behaviors improves credibility and ability to motivate. Arch Fam Med 2000, 9:287-290.

7. Kaiser P, Noack A, Donner-Banzhoff N, Keller S, Baum E: Hausärztinnnen und Hausärzte als Gesundheitsvorbilder? Ein Vergleich des Gesundheitsverhaltens von HausärztInnen und RechtsanwältInnen. Z Allg Med 2005, 81:419-422.

8. Frank $E$, Rothenberg R, Lewis C, Belodoff BF: Correlates of physicians' prevention-related practices. Findings from the Women Physicians' Health Study. Arch Fam Med 2000, 9:359-367.

9. Klewer ], Kugler J: [Vaccination status of medical and dental students]. Gesundheitswesen 2000, 62:654-659.

10. Voigt K, Kuhne F, Twork S, Gobel A, Kugler J, Bergmann A: [Current vaccination status of health-care personnel in Brandenburg, Saxony And Saxony-Anhalt] 5. Gesundheitswesen 2008, 70:408-4I4.

II. Burger M, Mensink G: Bundes-Gesundheitssurvey: Alkohol. Konsumverhalten in Deutschland. Berlin, Saladruck. Beiträge zur Gesundheitsberichterstattung des Bundes. Robert-Koch-Institut; 2003.

12. Bloomfield K, Kraus B, Soyka M: Gesundheitsberichterstattung des Bundes. Heft 40: Alkoholkonsum und alkoholbezogene Störungen. Berlin 2008.

13. European Community Health Indicators Monitoring: International Compendium of Health Indicators. [http://www.healthindica tors.org/lCHI/(nzufyou5ibnote550nnqcf55)/general/Searchln dicar.aspx]. 17-12-2008

14. Primary Health Care European Project on Alcohol: Describing alcohol consumption and alcohol related. [http://www.gen cat.cat/salut/phepa/units/phepa/html/en/dir35l/doc 9430 html]. 3-50006

15. Reid MC, Fiellin DA, O'Connor PG: Hazardous and Harmful Alcohol Consumption in Primary Care. Arch Intern Med 1999 I59:1681-1689.

16. Sächsische Landesärztekammer. Tätigkeitsbericht der Sächsischen Landesärztekammer 2004 [http://www.slaek.de]. [last access: 21.05.2008]. 2005.

17. Landesärztekammer Brandenburg. Berufstätige Ärzte am 31.12.2006 nach Anerkennung, Altersgruppe und Geschlecht Land Brandenburg gesamt [http://www.laekb.de/50ueberUns/]. [last access 21.05.2008]. 16-2-2007.

18. Landesärztekammer Brandenburg. Berufstätige Ärzte am 31.12.2006 nach Anerkennung, Art der Tätigkeit und Geschlecht Land Brandenburg gesamt [http://www.laekb.de]. [last access: 21.05.2008]. 4-6-0007.

19. Maniecka-Bryla I, Bryla M, Weinkauf A, Dierks ML: [The international comparative study of the health status of medical university students in Lodz and Hanover] 3. Przegl Lek 2005, 62(Suppl 3):63-68.

20. European Commission: Special Eurobarometer - Report 272b: Attitudes towards Alcohol. 2007 [http://ec.europa.eu/health/ ph determinants/life style/Tobacco/Documents/ebs272c en.pdf] [last access on 21.12.2008]. Ref Type: Electronic Citation

21. Burger $M$, Brönstrup A, Pietrzik $K$ : Alkoholkonsum und Krankheiten. Bd. 134. 2000. Baden-Baden, Nomos Verlagsgesellschaft. Schriftenreihe des Bundesministeriums für Gesundheit. Bundesministerium für Gesundheit .

22. Statistisches Bundesamt Deutschland $(\mathrm{Hg}$.): Gesundheitsbericht für Deutschland, 1998. Statistisches Bundesamt Deutschland. Bonn 1998.

23. Bühler A, Kröker C: Expertise zur Prävention des Substanzmissbrauchs. Forschung und Praxis der Gesundheitsförderung Band 29. Köln 2006

24. Kühn J, Westermann J: Praktisches Jahr - Zwischen Patientenwohl und "Hammerexamen". Dtsch Ärztebl 2006, 103:AI654-A1656.

25. Stößel U: Gesundheit und Gesundheitsverhalten beim Medizinernachwuchs. In Hofmann, Reschauer, and Stößel. [Band 19] Arbeitsmedizin im Gesundheitsdienst; 2006:205-222.

26. Frank E, Brogan DJ, Mokdad AH, Simoes EJ, Kahn HS, Greenberg RS Health-related behaviors of women physicians vs other women in the United States. Arch Intern Med 1998, I 58:342-348.

27. European Commission: Special Eurobarometer - Report 272c: Attitudes of Europeans towards Tobacco. 2007 [http:ec.europa.eu/health/ph determinants/life style/Tobacco/Docu 
ments/ebs272c en.pdf]. [last access on 21.12.2008]. Ref Type: Electronic Citation

28. Schulze A, Lampert T: Bundes-Gesundheitssurvey: Soziale Unterschiede im Rauchverhalten und in der Passivrauchbelastung in Deutschland. Robert-Koch-Institut. Berlin, Mercedesdruck. Beiträge zur Gesundheitsberichterstattung des Bundes; 2006.

29. Frank E, Carrera JS, Elon L, Hertzberg VS: Basic demographics, health practices, and health status of U.S. medical students. Am J Prev Med 2006, 31:499-505.

30. Deutsches Netz Rauchfreier Krankenhäuser.Rauchfreie Krankenhäuser 2008 [http://www.dnrfk.de/files/]. [last access: 21.05.2008]. 2008.

31. Laure $P$, Binsinger $C$ : Consommation de produits "aux fins de performance" par les médecins généralistes. Thérapie 2003, 58:445-450.

32. Barsch G, Plöttner C: Drogenkonsum und Drogenarbeit: Was ist in den Neuen Bundesländern anders? In Drogen - HIVIAIDS Hepatitis: Ein Handbuch Edited by: Klee J, Stöver H. Berlin; 2004.

33. Trkulja V, Zivcec Z, Cuk M, Lackovic Z: Use of psychoactive substances among Zagreb University medical students: followup study 120. Croat Med J 2003, 44:50-58.

34. Reimer C, Jurkat HB, Mäulen B, Stetter F: Zur Problematik der Suchtgefährdung von berufstätigen Medizinern. Lebensqualität und Gesundheitsverhalten von Ärztinnen und Ärzten mit und ohne Substanzabhängigkeit. Psychotherapeut 200I, 46:376-385.

35. Adams EH, Dart RC, Knisely JS, Schnoll SH: Tramadol abuse and dependence among physicians. JAMA 2005, 293:1977-1978.

36. Boniatti MM, Zubaran C, Panarotto D, Delazeri GJ, Tirello JL, Feldens $\mathrm{MO}$, et al:: The use of psychoactive substances among medical students in southern Brazil I 279. Drug Alcohol Rev 2007, 26:279-285

37. Kenna GA, Wood MD: The prevalence of alcohol, cigarette and illicit drug use and problems among dentists I8. J Am Dent Assoc 2005, I 36: 1023-1032.

38. Shaw MF, McGovern MP, Angres DH, Rawal P: Physicians and nurses with substance use disorders 5. J Adv Nurs 2004, 47:561-57I.

\section{Pre-publication history}

The pre-publication history for this paper can be accessed here:

http://www.biomedcentral.com/1472-6963/9/219/pre

pub
Publish with Biomed Central and every scientist can read your work free of charge

"BioMed Central will be the most significant development for disseminating the results of biomedical research in our lifetime. "

Sir Paul Nurse, Cancer Research UK

Your research papers will be:

- available free of charge to the entire biomedical community

- peer reviewed and published immediately upon acceptance

- cited in PubMed and archived on PubMed Central

- yours - you keep the copyright
BioMedcentral 